Corresponding author: beggs@enders.tch.harvard.edu

(c) 2019 Marttila et al. This article is distributed under the terms of the Creative Commons

Attribution-NonCommercial License, which permits reuse and redistribution, except for commercial purposes, provided that the original author and source are credited.

Ontology terms: abnormality of the musculature of the limbs; dilated cardiomyopathy; generalized muscle weakness; generalized neonatal hypotonia; polyhydramnios; skeletal myopathy; type 1 fibers relatively smaller than type 2 fibers

Published by Cold Spring Harbor Laboratory Press

doi:10.1101/mcs.a004184

\section{MYL2-associated congenital fiber-type disproportion and cardiomyopathy with variants in additional neuromuscular disease genes; the dilemma of panel testing}

\author{
Minttu Marttila, ${ }^{1}$ Wathone Win, ${ }^{1}$ Fouad Al-Ghamdi, ${ }^{1,2}$ Hoda Z. Abdel-Hamid, ${ }^{3,4}$ \\ David Lacomis, ${ }^{5}$ and Alan H. Beggs ${ }^{1}$ \\ ${ }^{1}$ Division of Genetics and Genomics, The Manton Center for Orphan Disease Research, Boston Children's \\ Hospital and Harvard Medical School, Boston, Massachusetts 02115, USA, ${ }^{2}$ King Fahad Specialist Hospital, \\ Dammam 32253, Saudi Arabia; ${ }^{3}$ Department of Pediatrics, Child Neurology Division, University of Pittsburgh, \\ Pittsburgh, Pennsylvania 15260, USA, ${ }^{4}$ Pediatric MDA Clinic, Division of Child Neurology, Children's Hospital \\ of Pittsburgh of UPMC, Pittsburgh, Pennsylvania 15224, USA, ${ }^{5}$ Neuromuscular Division, University of \\ Pittsburgh School of Medicine, Pittsburgh, Pennsylvania 15213, USA
}

Abstract Next-generation sequencing has led to transformative advances in our ability to diagnose rare diseases by simultaneously sequencing dozens, hundreds, or even entire genomes worth of genes to efficiently identify pathogenic mutations. These studies amount to multiple hypothesis testing on a massive scale and not infrequently lead to discovery of multiple genetic variants whose relative contributions to a patient's disease are unclear. Panel testing, in particular, can be problematic because each of the many genes being sequenced might represent a plausible explanation for a given case. We performed targeted gene panel analysis of 43 established neuromuscular disease genes in a patient with congenital fibertype disproportion (CFTD) and fatal infantile cardiomyopathy. Initial review of variants identified changes in four genes that could be considered relevant candidates to cause this child's disease. Further analysis revealed that two of these are likely benign, but a homozygous frameshift variant in the myosin light chain 2 gene, MYL2, and a heterozygous nonsense mutation in the nebulin gene, NEB, met criteria to be classified as likely pathogenic or pathogenic. Recessive MYL2 mutations are a rare cause of CFTD associated with both skeletal and cardiomyopathy, whereas recessive NEB mutations cause nemaline myopathy. Although the proband's phenotype is likely largely explained by the MYL2 variant, the heterozygous pathogenic NEB variant cannot be ruled out as a contributing factor. This case illustrates the complexity when analyzing large numbers of variants from targeted gene panels in which each of the genes might plausibly contribute to the patient's clinical presentation.

[Supplemental material is available for this article.]

\section{INTRODUCTION}

The term congenital myopathy (CM) encompasses a spectrum of clinically, histologically, and genetically variable neuromuscular disorders, many of which are caused by mutations in genes for sarcomeric proteins. Classified mainly on the basis of their histopathology, they share many clinical features, including hypotonia and proximal or generalized, and often 
nonprogressive, muscle weakness typically present from birth. The severity of weakness and disability varies widely from neonates with profound hypotonia and generalized weakness to patients with weakness that first manifests during childhood through delayed motor milestones or later in life with proximal weakness (North et al. 2014; Dowling et al. 2015). Serum creatine kinase levels are usually within normal limits but may be mildly to moderately elevated. The clinical manifestations of most CMs are limited largely to skeletal muscle, consistent with the restricted expression patterns of many CM genes; however, mutations of more broadly expressed genes, such as that for myotubularin, may lead to subtle findings in other organ systems (Herman et al. 1999; Beggs et al. 2018), and defects in genes with both skeletal and cardiac muscle expression, such as titin, may lead to either a predominantly skeletal or cardiac myopathy or both (Herman et al. 2012; Ceyhan-Birsoy et al. 2013).

Traditionally histology has been used as the basis to subcategorize the $\mathrm{CMs}$, and diagnoses are based on the presence of diagnostic pathological findings in the context of primary hypotonia or weakness. Reflecting their relatively nonprogressive course, muscle biopsies typically lack evidence for a dystrophic process of myofiber death and regeneration but instead are characterized by relatively stable and unique ultrastructural defects. Some of the most commonly recognized conditions include the nemaline (rod body) myopathies (NMs), core myopathies (such as central core and multiminicore diseases), the centronuclear/myotubular myopathies, and isolated fiber-type disproportions. Each clinicopathological diagnosis is genetically heterogeneous. For example, although recessive nebulin gene (NEB) mutations are responsible for about half of NM cases (Lehtokari et al. 2014), there are upward of a dozen different genes associated with NM (North et al. 2014; Dowling et al. 2015). Furthermore, mutations of many CM genes can cause a variety of distinct histopathological and clinical presentations-for example, mutations of the TPM2 gene encoding skeletal muscle tropomyosin, which can present as cap myopathy, NM, congenital fiber-type disproportion (CFTD), Escobar syndrome, or distal arthrogryposis (Marttila et al. 2014). Further complicating diagnosis is the fact that many of these features can be found together-for example, families in whom some affected members may have either nemaline rods or CFTD or both (Marttila et al. 2014) or co-occurrence of rods and cores (Agrawal et al. 2007).

Fiber-type disproportions, particularly with abnormally small type 1 fibers, are fairly common in muscle biopsies from patients with a variety of $\mathrm{CMs}$, and when paired with prominent nemaline bodies or cores are typically considered secondary nondiagnostic findings. However, patients with primary skeletal muscle weakness whose muscle exhibits only small type 1 fibers have been classified as having CFTD (DeChene et al. 2007; Clarke 2011). Most cases of CFTD are associated with mutations in TPM3, encoding the type 1 fiber-specific slow a-tropomyosin (Clarke et al. 2008; Lawlor et al. 2010), but there is a plethora of other muscle genes whose mutations have been found in patients meeting criteria for CFTD, including ACTA1 (Laing et al. 2004), MYH7 (Sobrido et al. 2005), RYR1 (Clarke et al. 2010), SELENON/SEPN1 (Clarke et al. 2006), and TPM2 (Clarke et al. 2012). Mutations of the LMNA gene, coding for lamin $A / C$, have also been identified in several Japanese patients with fiber-type disproportion, although these cases were characterized by type 2 fiber hypertrophy rather than type 1 hypotrophy, raising the question of whether they qualify as classical CFTD (Kajino et al. 2014). Finally, although these conditions are exclusively skeletal myopathies, type 1 fiber disproportion and weakness have also been found in association with cardiomyopathy in infants with ventricular/slow-twitch skeletal regulatory myosin light chain (MYL2) mutations (Weterman et al. 2013).

We subjected a cohort of patients with a variety of $\mathrm{CM}$ diagnoses to diagnostic gene panel sequencing of 43 genes associated with primary skeletal or cardiac myopathies. Here we describe one unusual case in whom we identified a predicted pathogenic homozygous frameshift variant in MYL2 as well as a heterozygous truncating nebulin (NEB) mutation. Because truncating null mutations of NEB are a known cause of NM, this case forced a 
reappraisal of the diagnosis and consideration of potential digenic inheritance. Although ultimately the infant's phenotype was considered to be fully explained by the homozygous MYL2 variant, the secondary finding of a pathogenic NEB mutation illustrates an increasingly common dilemma in cases subjected to targeted gene panel testing.

\section{RESULTS}

\section{Clinical Presentation and Family History}

The proband was a boy who presented with generalized hypotonia and head lag at birth. $\mathrm{He}$ was delivered at full term by cesarean section because of decreased fetal movement and bradycardia during induction. He had normal birth weight, length, and head circumference. Newborn exam revealed normal first and second heart sound with gallop rhythm and palpable liver at the right costal margin, as well as generalized hypotonia and diminished reflexes. Echocardiogram was performed at $11 \mathrm{~d}$ of age and revealed patent foramen ovale with left to right shunt and right atrial enlargement. He was discharged home with no respiratory or feeding support. His mother was a primigravida 20 -yr old with learning disability and hearing loss; she denied smoking, drinking, or using illicit drugs before or during pregnancy. She had multiple ultrasound studies that were remarkable only for polyhydramnios. The father was a healthy 20-yr old with no particular medical concerns, and there was no family history of neuromuscular or genetic disorders on either side. The proband continued to show poor head control and generalized hypotonia and weakness throughout the neonatal period and beyond. A vastus lateralis biopsy performed at 5 mo of age because of persistent muscle weakness and hypotonia revealed variability in fiber size with checkerboard pattern of 1:1 ratio of type 1 and type 2 fibers exhibiting hypotrophy of type 1 fiber size in comparison to the type 2 fibers (Fig. 1). Gomori trichrome-stained light micrographs and electron microscopy (EM) showed no evidence of ragged red fibers or nemaline rods, and oxidative stains revealed no evidence of cores, targetoid, or target fibers. Genetic testing was performed for DNA polymerase $\gamma$, catalytic subunit (POLG) and Noonan syndrome genes (PTPN11, SOS1, KRAS, RAF1, BRAF, MAP2K1, MAP2K2, and HRAS), all of which were normal. There was no histopathologic evidence of Pompe disease and GAA enzyme-level testing was normal. Muscular dystrophy was considered unlikely given the histopathologic findings and normal serum creatine kinase level.

At age $5 \mathrm{mo}$, the proband was admitted to hospital in decompensated heart failure and intubated on inotropic support. He was stabilized and successfully extubated and sent home on captopril, digoxin, Lasix, aspirin, and ubiquinone while being evaluated for heart transplant. One month later, he presented to the emergency department in what appeared to be decompensated cardiogenic shock, with severe respiratory distress, poor peripheral perfusion, and high lactate level $(7.8 \mathrm{mmol} / \mathrm{L})$. Again, he was admitted and intubated on inotropic support in the cardiac intensive care unit. Echocardiography revealed left ventricular dilatation, mild to moderate mitral valve regurgitation, and left atrial enlargement, with left ventricular function moderately to severely decreased with shortening fraction of $12 \%$ and ejection fraction of $23 \%$. Following an unsuccessful attempt to extubate, respiratory support was withdrawn $1 \mathrm{wk}$ later and the patient passed away.

\section{Genomic Analyses}

Written informed consent for research-based genetic testing was obtained from both parents under the supervision of the Boston Children's Hospital Institutional Review Board. Panel testing of 43 neuromuscular disease-related genes (Supplemental Table S1) led to the identification of four variants of particular concern for potential causal relationships to 

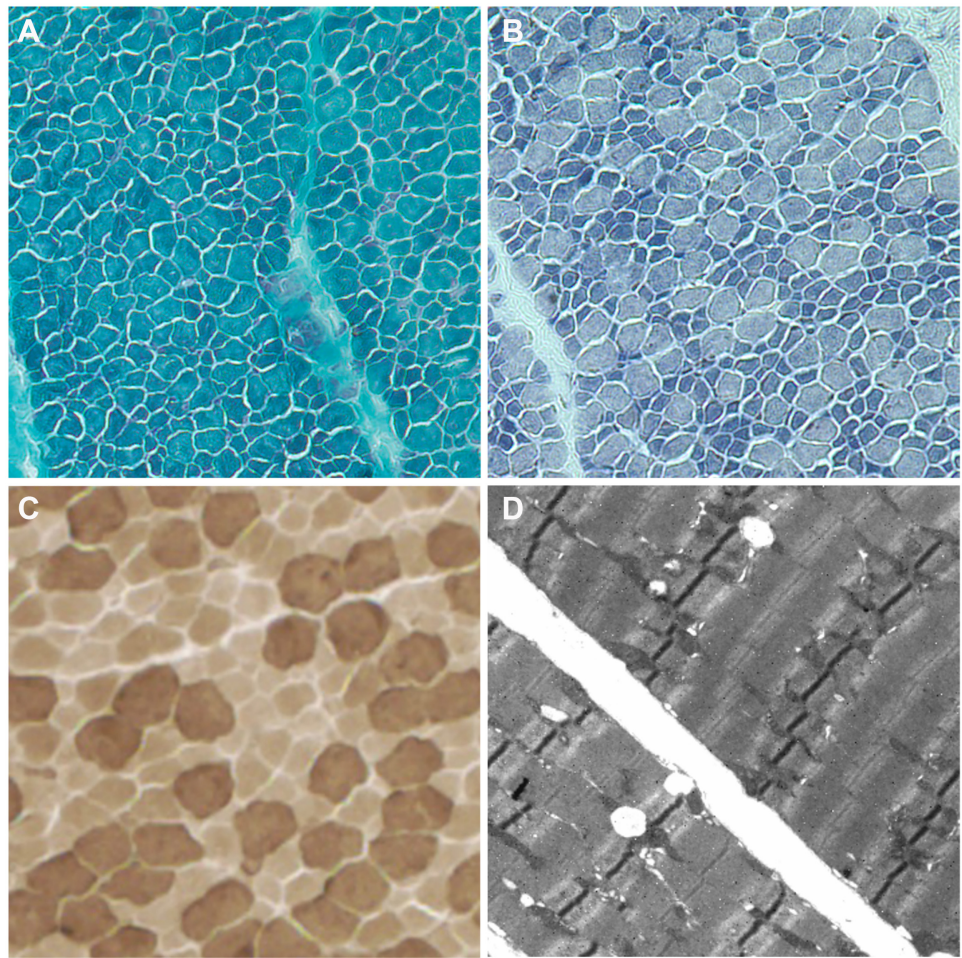

Figure 1. Microscopic examination substantiates the diagnosis of congenital fiber-type disproportion (CFTD). (A) Gomori trichrome staining does not reveal ragged red fibers or rimmed vacuoles. No definite nemaline rods are seen. Intramuscular nerve twigs are myelinated. (B) NAHD-TR-reacted sections reveal no cores, targetoid, or target fibers. Slight predominance of type 1 fibers is seen. Type 1 fibers are significantly smaller than type 2 fibers (mean type 2 fiber diameter-mean type 1 fiber diameter/mean type 2 fiber diameter $=40 \%$ ). (C) ATPase ( $\mathrm{pH}$ 9.4) staining reveals the slight predominance of type 1 fibers and type 1 fiber hypotrophy.

(D) Electron microscopy (EM) does not show any evidence of nemaline bodies.

the proband's condition (Table 1; Supplemental Table S2). The proband was homozygous for variant NM_000432.3:c.188del, p.(Asn63Metfs*7) in MYL2, predicted to be pathogenic according to ACMG criteria (Supplemental Table S3; Richards et al. 2015). In addition, he had a paternally inherited heterozygous truncating NEB variant NM_001271208.2: c. $25435 \mathrm{C}>\mathrm{T}$, p.(GIn8479*) predicted to be pathogenic. Both of these were Sanger con-

\begin{tabular}{|c|c|c|c|c|c|c|c|c|}
\hline Gene & $\mathrm{Chr}$ & HGVS DNA reference & $\begin{array}{l}\text { HGVS protein } \\
\text { reference }\end{array}$ & $\begin{array}{l}\text { Variant } \\
\text { type }\end{array}$ & $\begin{array}{l}\text { Predicted } \\
\text { effect }\end{array}$ & dbSNP ID & Genotype & ClinVar ID \\
\hline MYL2 & 12 & NM_000432.3: c.188del & $\begin{array}{l}\text { NP_000423.2: } \\
\text { p.(Asn63Metfs*7) }\end{array}$ & Deletion & Frameshift & rs1177936172 & Homozygous & NA \\
\hline NEB & 2 & $\begin{array}{l}\text { NM_001271208.2: } \\
\text { c. } 25435 \mathrm{C}>\mathrm{T}\end{array}$ & $\begin{array}{l}\text { NP_001258137.2: } \\
\text { p.(Gln8479*) }\end{array}$ & Substitution & Stop-gained & rs778104284 & Heterozygous & NA \\
\hline TTN & 2 & $\begin{array}{l}\text { NM_001267550.2: } \\
\text { c.33513_33515dup }\end{array}$ & $\begin{array}{l}\text { NP_001254479.2: } \\
\text { p.(Glu11172dup) }\end{array}$ & Duplication & Insertion & rs368327166 & Heterozygous & 46889 \\
\hline DMD & $x$ & $\begin{array}{l}\text { NM_004021.2: } \\
\text { c.3669_3681del }\end{array}$ & $\begin{array}{l}\text { NP_004012.1: } \\
\text { p.(Asp1223Glufs*6) }\end{array}$ & Deletion & Frameshift & rs752332058 & Hemizygous & 201754 \\
\hline
\end{tabular}

(Chr) Chromosome, (HGVS) Human Genome Variation Society, (NA) not available. 
A

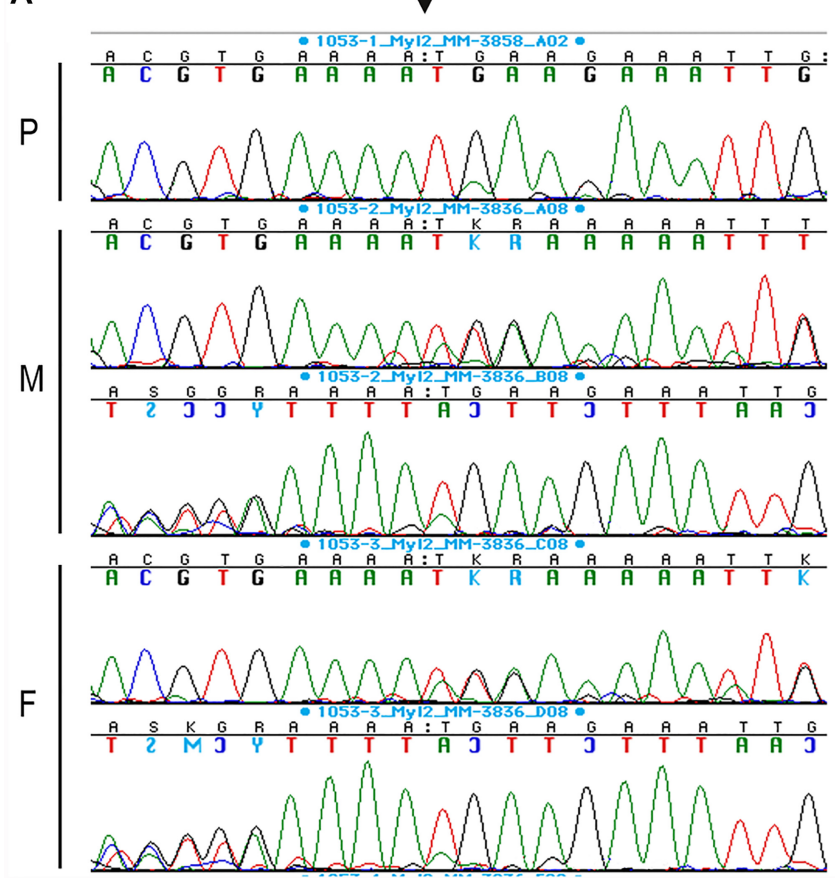

B

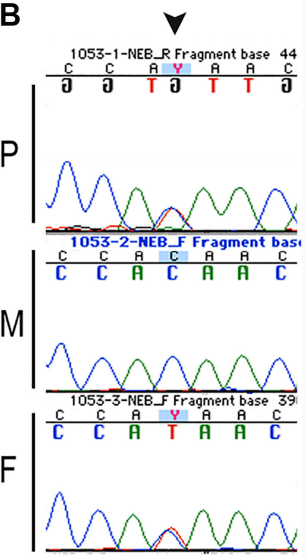

Figure 2. (A) DNA Sanger sequencing results of the proband (" $P$, " 1053-1, top tracing), mother (" $M$," 1053-2), and father ("F," 1053-3), illustrating the myosin light chain-2 (MYL2) c.188del p.(Asn63Metfs* 7) variant (arrowhead). Sequencing reads for parents are shown in both directions, demonstrating that they are heterozygous and proband homozygous for the mutation. (B) The proband (" $P$," top) also has heterozygote truncating nebulin (NEB) mutation c.25435C>T p.(Gln8479*) (arrowhead). The father ("F," bottom), but not the mother ("M," middle) also carries this heterozygous variant.

firmed in the proband and his parents (Fig. 2). The patient was also heterozygous for a titin (TTN) variant NM_001267550.2:c.33513_33515dup, p.(Glu11172dup) and hemizygous for NM_004021.2:c.3669_3681del, p.(Asp1223Glufs*6) in the DMD gene, both of which were later determined to be benign or likely benign (Supplemental Table S3).

\section{DISCUSSION}

We report a novel case of CFTD and infantile onset cardiomyopathy associated with pathogenic variants in the MYL2 and NEB genes. Myosin light chain-2 (MYL2/MLC-2) is a major sarcomeric protein of the thin filament in mammalian striated muscle of $\sim 19 \mathrm{kDa}$ and 166 amino acids in length (Sheikh et al. 2015). This myosin regulatory light chain is expressed in slow skeletal, type 1 fibers, as well as in ventricular cardiac myocytes, where it plays a role in cross-bridge cycling kinetics and calcium-dependent cardiac muscle contraction. Dominant missense mutations were first shown to be associated with hypertrophic cardiomyopathy (Poetter et al. 1996), but recently recessive frameshift mutations, affecting the last exon and associated with severe reduction or loss of detectable protein, were reported to cause a fatal infantile cardiomyopathy, with skeletal muscle involvement similar to that of our proband (Weterman et al. 2013).

Nebulin is a fundamental structural component of the skeletal muscle sarcomeric thin filament and is not expressed in the heart. It has 183 exons spanning $249 \mathrm{~kb}$ of genomic sequence, and recessive loss of function, and some missense variants, are the most 
common cause of NM (Donner et al. 2004). Our analysis concluded that the proband's severe infantile cardiomyopathy and lack of evidence for nemaline rods were most consistent with the effects of the homozygous frameshift variant in MYL2, c.188del, p.Asn63Metfs*7. A single heterozygous allele of this variant has been reported in a healthy female from the Finnish cohort in gnomAD, for an overall population allele frequency of $3.976 \times 10^{-6}$ and has not been seen in any other population or disease-specific databases including 1000 Genomes, the Human Gene Mutation Database, or The Leiden Open Variation Database. Indeed, there are no instances of individuals homozygous for truncating MYL2 variants in the entire gnomAD data set. MYL2 c.188del p.(Asn63Metfs*7) has a scaled CADD score of 35 (Rentzsch et al. 2019) and, according to ACMG criteria, can be classified as "pathogenic" (Supplemental Table S3).

Recessive stop-gain and frameshift variants such as the NEBp.(Gln8479*) found in our proband occur throughout the gene and are invariably disease-causing when present in a biallelic relationship with another predicted truncating variant (Lehtokari et al. 2014). Residue GIn8479 is in the last exon of the major muscle transcript, so truncation at this pointmay or may not destabilize the transcript; however, there are least two additional pathogenic truncating variants distal to p.Gln8479 in the nebulin Leiden Open Variation Database (Fokkema et al. 2011), supporting a pathogenic interpretation for this variant, which also has a high scaled CADD score of 60 . Nevertheless, all NEB mutations reported to date have invariably been recessive, and careful inspection of the panel data, including VisCap analysis for copy-number variation indicative of a gross deletion or duplication (Pugh et al. 2016), failed to identify a second potentially pathogenic NEB allele (data not shown), making this paternally inherited heterozygous variant less likely to be a significant contributor to disease in our proband. Furthermore, although mutations of nebulin have previously been associated with a variety of clinical presentations, including NM (Pelin et al. 1999), early-onset distal myopathy without nemaline bodies (Wallgren-Pettersson et al. 2007), a distal form of NM (Lehtokari et al. 2011), core-rod myopathy with generalized muscle weakness (Romero et al. 2009), and a childhoodonset distal myopathy with rods and cores (Scoto et al. 2013), none of these conditions feature significant cardiac pathology, consistent with the lack of NEB expression in the heart.

Although nebulin and myosin light chain-2 are not known to directly bind or interact, they have close functional associations because of their respective roles in sarcomeric thick and thin filaments, respectively. Therefore, it is worthwhile to consider whether heterozygosity for the truncating NEB variant might function as a modifier for the effects of the homozygous MYL2 variant in skeletal muscle. However, the absence of nemaline rods on Gomori trichrome-stained light micrographs and on electron micrographs failed to provide evidence in support of this hypothesis, and the clinical presentation was entirely consistent with previous reports of patients with MYL2 skeletal and cardiomyopathy.

Variants in the titin gene, TTN, and in that for dystrophin, DMD, were also flagged in the initial analysis but were more easily excluded from further consideration. The NM_001267550.2:c.33513_33515dup, p.(Glu11172dup) variant in TTN is predicted to be likely benign or benign in ClinVar largely based on its allele frequency of up to 0.0179 in Europeans and presence of 24 homozygotes across all populations in gnomAD. Given that we have also seen this allele in individuals with no evidence for a titin-related myopathy, we considered this unlikely to be a contributing factor to our proband's condition.

The DMD variant NM_004021.2:c.3669_3681del, p.(Asp1223Glufs*6) was also considered unlikely to be relevant. Not only did the proband have normal CK levels and absence of dystrophic findings on muscle biopsy, but this 13-base indel is in the $3^{\prime}$ untranslated region of the large primary skeletal muscle dystrophin transcript and affects only the very carboxyl terminus of the minor Dp71 and Dp141 transcripts. Given that this variant is present at an allele frequency of 0.00025 in gnomAD, including 13 hemizygous males ranging in age from 30 to 75, we consider it likely benign, which is consistent with an entry in ClinVar. 
Clinical heterogeneity resulting from variable expressivity associated with some genes and variants is common among neuromuscular disorders: The same genetic mutation may lead to different pathological features in members of the same family or in the same individual over time (Bönnemann et al. 2014). For example, mutations in TPM3 have been reported in both CFTD and nemaline myopathy (NM) in members of the same family (Lawlor et al. 2010). Age, genetic modifiers, environmental factors, or the site of the muscle biopsy may influence the pathological appearance of skeletal muscle (North and Laing 2008). Another example is mutations of SELENON (formerly SEPN1), which can result in rigid spine muscular dystrophy, desmin-related myopathy with Mallory body-like inclusions, or CFTD (Dowling et al. 2015). These examples suggest that different mutations in the same gene can affect different pathogenetic pathways within the muscle sarcomere, making variant interpretation difficult when considering variants in multiple neuromuscular disease-associated genes.

Heterozygous missense mutations of MYL2 have previously been associated with hypertrophic cardiomyopathy (Poetter et al. 1996). More recently, two instances of recessive MYL2 mutations have been reported to cause a novel autosomal recessive lethal myosinopathy with infantile type I muscle fiber disease and cardiomyopathy (Weterman et al. 2013). One of these, a homozygous intronic mutation of $M Y L 2, c .403-1 \mathrm{G}>C$, in a group of related Dutch families resulted in replacement of the last 32 codons with 19 new amino acids. Functional analysis of the resulting protein demonstrated significant conformational alterations and a series of abnormal protein-protein interactions in the cardiac muscle sarcomere, leading to decreased maximal contractile force production and increased calcium sensitivity (Zhou et al. 2016), features that likely play a role in the pathogenesis of cardiac failure in our proband. The second instance was found in two Italian siblings with compound heterozygous mutations, c.431delC, p.(Pro144LeufsX2) and c.432delT, p.(Asp145ThrfsX2), in the last exon that both resulted in loss of 20 amino acids at the carboxyl terminus (Weterman et al. 2013). Both the Dutch and Italian infants died between the ages of 1 and 6 mo, consistent with the clinical course of our proband. Given the location of our proband's truncation in the middle of the protein and presumed consequent complete loss of function, it may be that the carboxy-terminal mutations in the Dutch and Italian infants with similar severity also lead to loss of function, especially because western blot and immunohistochemical staining for MYL2 protein revealed low or undetectable levels of protein in the Dutch patients (Weterman et al. 2013).

Careful assessment of molecular consequences, such as predicted effects of the frameshift mutation in the last exon of NEB or differential effects on multiple transcripts, as with the $D M D$ variant that spared the major full-length muscle isoform, are critical for proper variant interpretation. Careful assessment of the clinical phenotype is equally critical when considering potential relationships between pathogenic variants and a patient's medical condition. Although the proband in this study was enrolled on the basis of his hypotonia, weakness, and CFTD in skeletal myofibers, his early-onset fatal cardiomyopathy was a key factor in making a final diagnosis.

In conclusion, this case stresses the importance of multiple methods for variant interpretation and prediction of pathogenicity, including careful phenotyping and correlation with clinical findings, especially when multiple variants are found in genes related to the clinical presentation.

\section{METHODS}

\section{Next-Generation Panel Testing}

Next-generation sequencing was performed by the Laboratory for Molecular Medicine (LMM) of Partners Healthcare Personalized Medicine using the Agilent SureSelect Design process 
COLD SPRING HARBOR Molecular Case Studies
CFTD and cardiomyopathy associated with MYL2 (http://personalizedmedicine.partners.org/laboratory-for-molecular-medicine/). The gene panel utilized an all exon approach for 43 genes of interest for neuromuscular and cardiac conditions (Supplemental Table S1) by targeting coding exons with bait out to coding sequence (CDS) \pm 65 bases. The complete coding regions of all genes were sequenced to average depth of 316 reads, with the exception of CFL2, NEB, SEPN1, TNNT1, and TTN, for which a few exons were excluded because of difficulties in capture. The reportable region of interest was CDS \pm 15 bases. For density of probes, a $3 \times$ tiling strategy was used. For masking and boosting, a moderately stringent option and maximum performance conditions were used respectively. Specifically, for the DMD gene, in addition to covering all CDS exons \pm 65 , deletion probes were created every $30 \mathrm{~kb}$ within the gene region at a $1 \times$ tiling. Next-generation sequencing of paired-end reads was performed on an Illumina HiSeq platform.

\section{In Silico Analysis}

Variant calls were generated using the Burrows-Wheeler Aligner, followed by the Genomic Analysis Tool Kit (GATK). Candidate variants were assessed by reference to the Human Gene Mutation Database (HGMD http://www.hgmd.cf.ac.uk/ac/index.php), ClinVar (https://www .ncbi.nlm.nih.gov/clinvar/), and the Genome Aggregation Consortium (gnomAD) database (http://gnomad.broadinstitute.org). Candidate variants that were known single-nucleotide polymorphisms (SNPs) were required to have a minor allele frequency of $<0.0001$ to be considered for further analysis. SNPs with a minor allele frequency of $>0.0001$ were considered to be nonpathogenic. Pathogenicity of variants was predicted by using SIFT (http://sift.jcvi .org), PolyPhen-2 (http://genetics.bwh.harvard.edu/pph2), and CADD (Rentzsch et al. 2019), and final determinations of pathogenicity were made following current American College of Medical Genetics guidelines for the interpretation of sequence variants (Richards et al. 2015).

\section{Sanger Sequencing Confirmation}

Selected variants were amplified by PCR using standard PCR primers. Amplicons were run in agarose gel electrophoresis and submitted to the Molecular Genetics Core Facility at Boston Children's Hospital for sequencing using the ABI Prism BigDye Terminator cycle sequencing protocols (Applied Biosystems, PerkinElmer Corp.). Sequence data were generated in an ABI Prism 3130 or 3730 Genetic Analyzer (Applied Biosystems), formatted by ABI Sequencing Analysis software v.5.2 and KB Basecaller, and analyzed using Sequencher v.5.2.3 or earlier versions (Gene Codes Corporation). Sanger sequencing was performed in affected family members and other family members to confirm pathogenic mutations and track cosegregation patterns.

\section{ADDITIONAL INFORMATION}

\section{Data Deposition and Access}

Variant c.188del p.(Asn63Metfs*7) in MYL2 has been submitted to Leiden Open Variation Database (LOVD) with ID number 00367860. Variant c.25435C>T p.(GIn8479*) in NEB has also been submitted to Leiden Open Variation Database (LOVD) with ID number 00163746. Additional variant calls from analysis of the 43 neuromuscular disease genes in the proband are available from the authors upon reasonable request.

\section{Ethics Statement}

The study was approved by the Boston Children's Hospital Institutional Review Board, with full written consent obtained from the parents, providing consent for the proband. 
Competing Interest Statement The authors have declared no competing interest.

Referees

Angharad M. Roberts

Anonymous

Received March 11, 2019; accepted in revised form May 16, 2019.

\section{Acknowledgments}

The authors would like to thank Ayano Kondo for technical assistance, Dr. Partha Gosh for helpful discussions regarding patient phenotype and involvement of mutations in the presentation, and Dr. Michael Lawlor for referral for subject enrollment. Thanks to staff of the Partner's Healthcare LMM for assistance interpreting results of their Neuromuscular Disease Panel Test.

\section{Author Contributions}

M.M. verified variants in the sequencing panel, produced the figures, and drafted the article; W.W. conducted Sanger confirmations; F.A.G. reviewed the clinical details of the patient; H.Z.A.-H. and D.L. referred the patient, provided ATPase histological staining, and reviewed the clinical details of the patient; and A.H.B. conceived the project, led the sequencing effort, interpreted variants, helped draft the manuscript, and edited the manuscript. All authors critically reviewed and approved the manuscript.

\section{Funding}

The study was supported by the National Institutes of Health (NIH) National Institute of Child Health and Human Development grant R01HD075802, NIH National Institute of Arthritis and Musculoskeletal and Skin Diseases grant R01AR044345, and Muscular Dystrophy Association USA grant MDA602235. M.M. received support from the Finnish Cultural Foundation, the Paulo Foundation, Lastentautien tutkimussäätiö, and Orion Research Foundation. Sanger sequencing was performed by the Boston Children's Hospital IDDRC Molecular Genetics Core Laboratory supported by NIH award U54HD090255 from the National Institute of Child Health and Human Development.

\section{REFERENCES}

Agrawal PB, Greenleaf RS, Tomczak KK, Lehtokari VL, Wallgren-Pettersson C, Wallefeld W, Laing NG, Darras BT, Maciver SK, Dormitzer PR, et al. 2007. Nemaline myopathy with minicores caused by mutation of the CFL2 gene encoding the skeletal muscle actin-binding protein, cofilin-2. Am J Hum Genet 80: 162-167. doi:10.1086/510402

Beggs AH, Byrne BJ, De Chastonay S, Haselkorn T, Hughes I, James ES, Kuntz NL, Simon J, Swanson LC, Yang $\mathrm{ML}$, et al. 2018. A multicenter, retrospective medical record review of X-linked myotubular myopathy: the recensus study. Muscle Nerve 57: 550-560. doi:10.1002/mus.26018

Bönnemann CG, Wang CH, Quijano-Roy S, Deconinck N, Bertini E, Ferreiro A, Muntoni F, Sewry C, Beroud C, Mathews KD, et al. 2014. Diagnostic approach to the congenital muscular dystrophies. Neuromuscul Disord 24: 289-311. doi:10.1016/j.nmd.2013.12.011

Ceyhan-Birsoy O, Agrawal PB, Hidalgo C, Schmitz-Abe K, DeChene ET, Swanson LC, Soemedi R, Vasli N, lannaccone ST, Shieh PB, et al. 2013. Recessive truncating titin gene, TTN, mutations presenting as centronuclear myopathy. Neurology 81: 1205-1214. doi:10.1212/WNL.0b013e3182a6ca62

Clarke NF. 2011. Congenital fiber-type disproportion. Semin Pediatr Neurol 18: 264-271. doi:10.1016/j.spen .2011.10.008

Clarke NF, Kidson W, Quijano-Roy S, Estournet B, Ferreiro A, Guicheney P, Manson JI, Kornberg AJ, Shield LK, North KN. 2006. SEPN1: associated with congenital fiber-type disproportion and insulin resistance. Ann Neurol 59: 546-552. doi:10.1002/ana.20761

Clarke NF, Kolski H, Dye DE, Lim E, Smith RL, Patel R, Fahey MC, Bellance R, Romero NB, Johnson ES, et al. 2008. Mutations in TPM3 are a common cause of congenital fiber type disproportion. Ann Neurol 63: 329337. doi:10.1002/ana.21308

Clarke NF, Waddell LB, Cooper ST, Perry M, Smith RL, Kornberg AJ, Muntoni F, Lillis S, Straub V, Bushby K, et al. 2010. Recessive mutations in RYR1 are a common cause of congenital fiber type disproportion. Hum Mutat 31: E1544-E1550. doi:10.1002/humu.21278 
Clarke NF, Waddell LB, Sie LT, van Bon BW, McLean C, Clark D, Kornberg A, Lammens M, North KN. 2012. Mutations in TPM2 and congenital fibre type disproportion. Neuromuscul Disord 22: 955-958. doi:10 .1016/j.nmd.2012.06.002

Dechene ET, Kang PB, Beggs AH. 2007. Congenital fiber-type disproportion. In GeneReviews ${ }^{\circledR}$ (ed. Adam MP, et al.), pp. 1993-2019. University of Washington, Seattle, WA.

Donner K, Sandbacka M, Lehtokari VL, Wallgren-Pettersson C, Pelin K. 2004. Complete genomic structure of the human nebulin gene and identification of alternatively spliced transcripts. Eur J Hum Genet 12: 744751. doi:10.1038/sj.ejhg.5201242

Dowling JJ, North KN, Goebel HH, Beggs AH. 2015. Congenital and other structural myopathies. In Neuromuscular disorders of infancy, childhood, and adolescence: a clinician's approach (ed. Darras BT, et al.), pp. 499-537. Elsevier, London.

Fokkema IF, Taschner PE, Schaafsma GC, Celli J, Laros JF, den Dunnen JT. 2011. LOVD v.2.0: the next generation in gene variant databases. Hum Mutat 32: 557-563. doi:10.1002/humu.21438

Herman GE, Finegold M, Zhao W, de Gouyon B, Metzenberg A. 1999. Medical complications in long-term survivors with X-linked myotubular myopathy. J Pediatr 134: 206-214. doi:10.1016/S0022-3476(99) 70417-8

Herman DS, Lam L, Taylor MR, Wang L, Teekakirikul P, Christodoulou D, Conner L, DePalma SR, McDonough B, Sparks E, et al. 2012. Truncations of titin causing dilated cardiomyopathy. N Engl J Med 366: 619-628. doi:10.1056/NEJMoa1110186

Kajino S, Ishihara K, Goto K, Ishigaki K, Noguchi S, Nonaka I, Osawa M, Nishino I, Hayashi YK. 2014. Congenital fiber type disproportion myopathy caused by LMNA mutations. J Neurol Sci 340: 94-98. doi:10.1016/j.jns .2014.02.036

Laing NG, Clarke NF, Dye DE, Liyanage K, Walker KR, Kobayashi Y, Shimakawa S, Hagiwara T, Ouvrier R, Sparrow JC, et al. 2004. Actin mutations are one cause of congenital fibre type disproportion. Ann Neurol 56: 689-694. doi:10.1002/ana.20260

Lawlor MW, Dechene ET, Roumm E, Geggel AS, Moghadaszadeh B, Beggs AH. 2010. Mutations of tropomyosin 3 (TPM3) are common and associated with type 1 myofiber hypotrophy in congenital fiber type disproportion. Hum Mutat 31: 176-183. doi:10.1002/humu.21157

Lehtokari VL, Pelin K, Herczegfalvi A, Karcagi V, Pouget J, Franques J, Pellissier JF, Figarella-Branger D, von der Hagen M, Huebner A, et al. 2011. Nemaline myopathy caused by mutations in the nebulin gene may present as a distal myopathy. Neuromuscul Disord 21: 556-562. doi:10.1016/j.nmd.2011.05.012

Lehtokari VL, Kiiski K, Sandaradura SA, Laporte J, Repo P, Frey JA, Donner K, Marttila M, Saunders C, Barth PG, et al. 2014. Mutation update: the spectra of nebulin variants and associated myopathies. Hum Mutat 35: 1418-1426. doi:10.1002/humu.22693

Marttila M, Lehtokari VL, Marston S, Nyman TA, Barnerias C, Beggs AH, Bertini E, Ceyhan-Birsoy O, Cintas P, Gerard M, et al. 2014. Mutation update and genotype-phenotype correlations of novel and previously described mutations in TPM2 and TPM3 causing congenital myopathies. Hum Mutat 35: 779-790. doi:10 $.1002 /$ humu.22554

North KN, Laing NG. 2008. Skeletal muscle a-actin diseases. Adv Exp Med Biol 642: 15-27. doi:10.1007/9780-387-84847-1_2

North KN, Wang CH, Clarke N, Jungbluth H, Vainzof M, Dowling JJ, Amburgey K, Quijano-Roy S, Beggs AH, Sewry C, et al. 2014. Approach to the diagnosis of congenital myopathies. Neuromuscul Disord 24: 97116. doi:10.1016/j.nmd.2013.11.003

Pelin K, Hilpela P, Donner K, Sewry C, Akkari PA, Wilton SD, Wattanasirichaigoon D, Bang ML, Centner T, Hanefeld $F$, et al. 1999. Mutations in the nebulin gene associated with autosomal recessive nemaline myopathy. Proc Natl Acad Sci 96: 2305-2310. doi:10.1073/pnas.96.5.2305

Poetter K, Jiang H, Hassanzadeh S, Master SR, Chang A, Dalakas MC, Rayment I, Sellers JR, Fananapazir L, Epstein ND. 1996. Mutations in either the essential or regulatory light chains of myosin are associated with a rare myopathy in human heart and skeletal muscle. Nat Genet 13: 63-69. doi:10.1038/ng0596-63

Pugh TJ, Amr SS, Bowser MJ, Gowrisankar S, Hynes E, Mahanta LM, Rehm HL, Funke B, Lebo MS. 2016. VisCap: inference and visualization of germ-line copy-number variants from targeted clinical sequencing data. Genet Med 18: 712-719. doi:10.1038/gim.2015.156

Rentzsch P, Witten D, Cooper GM, Shendure J, Kircher M. 2019. CADD: predicting the deleteriousness of variants throughout the human genome. Nucleic Acids Res 47: D886-D894. doi:10.1093/nar/gky1016

Richards S, Aziz N, Bale S, Bick D, Das S, Gastier-Foster J, Grody WW, Hegde M, Lyon E, Spector E, et al. 2015. Standards and guidelines for the interpretation of sequence variants: a joint consensus recommendation of the American College of Medical Genetics and Genomics and the Association for Molecular Pathology. Genet Med 17: 405-424. doi:10.1038/gim.2015.30

Romero NB, Lehtokari VL, Quijano-Roy S, Monnier N, Claeys KG, Carlier RY, Pellegrini N, Orlikowski D, Barois A, Laing NG, et al. 2009. Core-rod myopathy caused by mutations in the nebulin gene. Neurology 73: 1159-1161. doi:10.1212/WNL.0b013e3181bacf45 
Scoto M, Cullup T, Cirak S, Yau S, Manzur AY, Feng L, Jacques TS, Anderson G, Abbs S, Sewry C, et al. 2013. Nebulin (NEB) mutations in a childhood onset distal myopathy with rods and cores uncovered by next generation sequencing. Eur J Hum Genet 21: 1249-1252. doi:10.1038/ejhg.2013.31

Sheikh F, Lyon RC, Chen J. 2015. Functions of myosin light chain-2 (MYL2) in cardiac muscle and disease. Gene 569: 14-20. doi:10.1016/j.gene.2015.06.027

Sobrido MJ, Fernández JM, Fontoira E, Pérez-Sousa C, Cabello A, Castro M, Teijeira S, Álvarez S, Mederer S, Rivas $\mathrm{E}$, et al. 2005. Autosomal dominant congenital fibre type disproportion: a clinicopathological and imaging study of a large family. Brain 128: 1716-1727. doi:10.1093/brain/awh511

Wallgren-Pettersson C, Lehtokari VL, Kalimo H, Paetau A, Nuutinen E, Hackman P, Sewry C, Pelin K, Udd B. 2007. Distal myopathy caused by homozygous missense mutations in the nebulin gene. Brain 130: 1465-1476. doi:10.1093/brain/awm094

Weterman MA, Barth PG, van Spaendonck-Zwarts KY, Aronica E, Poll-The BT, Brouwer OF, van Tintelen JP, Qahar Z, Bradley EJ, de Wissel M, et al. 2013. Recessive MYL2 mutations cause infantile type I muscle fibre disease and cardiomyopathy. Brain 136: 282-293. doi:10.1093/brain/aws293

Zhou Z, Huang W, Liang J, Szczesna-Cordary D. 2016. Molecular and functional effects of a splice site mutation in the MYL2 gene associated with cardioskeletal myopathy and early cardiac death in infants. Front Physiol 7: 240 . doi:10.3389/fphys.2016.00240 


\section{COLD SPRING HARBOR Molecular Case Studies}

\section{MYL2-associated congenital fiber-type disproportion and cardiomyopathy with variants in additional neuromuscular disease genes; the dilemma of panel testing}

Minttu Marttila, Wathone Win, Fouad Al-Ghamdi, et al.

Cold Spring Harb Mol Case Stud 2019, 5: a004184 originally published online May 24, 2019

Access the most recent version at doi:10.1101/mcs.a004184

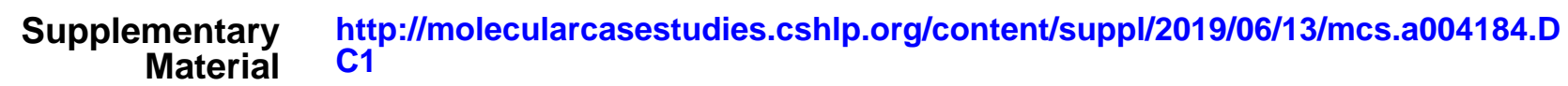

References This article cites 33 articles, 3 of which can be accessed free at:

http://molecularcasestudies.cshlp.org/content/5/4/a004184.full.html\#ref-list-1

License This article is distributed under the terms of the Creative Commons Attribution-NonCommercial License, which permits reuse and redistribution, except for commercial purposes, provided that the original author and source are credited.

Email Alerting Receive free email alerts when new articles cite this article - sign up in the box at the Service top right corner of the article or click here. 